\title{
Research on Henan Regional Cultural Industry Competitiveness Evaluation
}

\author{
Weiping Guo ${ }^{1, a}$ \\ ${ }^{1}$ Zhengzhou Technical College, Zhengzhou, Henan, China, 450121 \\ aemail,
}

Keywords: Henan Cultural Industry, Competitiveness, Regional Economic

\begin{abstract}
Development of cultural industry has strong regional features and characteristics of industrial clusters, factors affecting regional cultural industry competitiveness evaluation include production conditions, basic conditions, support industry conditions and institutional conditions. In regional comparison of several central provinces, the overall level the development of cultural industry in Henan Province is not high and lacks of highlights and other issues. Therefore, we should enhance the competitiveness of Henan Cultural Industry force from cultivating new production subject and innovation culture industry chain and other aspects.
\end{abstract}

\section{Introduction}

In recent years, cultural industry development in Henan Province showed faster growth of the body, centralized development trend, in 2013, Henan cultural industry exceeded 100 billion RMB, the construction of cultural Henan Province has pioneered the development momentum in the country is formed. But compared with the total economy in Henan Province, the proportion of the cultural industry in Henan Province is smaller, the low level of contribution to the national economy. 2013, Henan cultural industry accounts for 3.1\% of GDP, is located in Beijing (12.6\%), Guangdong (6.4\%), Shanghai (5.6\%), Fujian (316\%), Zhejiang (3.5\%) and other provinces after that, the cultural industry has not yet become a pillar industry in Henan Province. Therefore, from Henan Province, the construction of cultural province of overall requirements and regional economic development objective, cultural industry development in Henan province to achieve higher GDP growth rate, higher than the growth rate of the service sector has become a pillar industry of the national economy in Henan Province requirements, must be studied cultural industry competitiveness in Henan Province and its influencing factors.

\section{Affecting Factors of Cultural Industry Competitiveness in Regional Perspective}

Culture, by its very nature is an object-oriented and result of human practice. Intercultural economy and business contacts during the formation of the local labor market, prompting the polymerization production systems and geographical environment, the effects of high returns often appear also greatly improved momentum. This aggregation tendency and the associated effects of high returns, not only improve the efficiency of production systems, but also improve their creativity. This is not so apparent in the production of any other occasion. Therefore, the cultural industry has a tendency to polymerization on the geographical distribution, namely cluster development features. Meanwhile, the cultural industries rely on the cultural resources with a strong regional characteristics, the development of cultural industries not only require relatively concentrated on the geographical location, but also in the production and creation required to achieve regional coordination and mutual match. Therefore, compared to other areas of material production industries, cultural industries have a stronger regional characteristics.

Cultural industries as a location based marketing and integration of urban and regional strategy update a key factor in the economic development pattern, industrial structure optimization, the ability to foster innovation and regional economic development is important. Value from content and organizational structure of cultural industries, the cultural industry is a gradually expanding concentric circles, the core layer is the cultural content creation activities, the inner ring is to create 
cultural products, the outer ring is the issue of cultural products and services to retail industry, the extension ring is said to be sub-culture industry or the cultural industry and other industries fusion hybrid industry generated after. Therefore, the cultural industry is composed of many separate but related cultural enterprises and related supporting mechanism according to specialization and collaboration established, and organization of industrial clusters in certain areas of agglomeration and formation. Cultural industry clusters in the general sense to include all the upstream and downstream industry chain enterprise culture, namely the five main cultural industries: Creative body, making the body, the body spread, and extend the service principal body. Combining industrial competitiveness Porter Diamond Model and related cultural industry cluster theory, I believe that cultural factors affect industrial competitiveness mainly includes the following four aspects, namely 4-level indicators: cultural industry factors of production conditions, including: Culture resources, human resources, capital resources and infrastructure, four secondary indicators and 13 level indicators. Micro-foundation of cultural industries, production processes and consumption of two secondary indicators of cultural industries and include seven three indicators. Related support industry conditions, including four two indicators of information industry, education, industry, tourism industry and high-tech industries as well as 4-level indicators. Institutional conditions. In the cultural industry cluster development process, the government plays an integral role, a good, promote the formation of cultural industry development of the institutional environment, will have a profound impact in attracting capital, talent and promote cultural gathering related industries, etc. ,main

Including government investment and government legal support two secondary indexes as well as four-level indicators. Thus, the regional cultural industry competitiveness influencing factors on the basis of the principles of evaluation index system with related industries to build, we design the cultural industry competitiveness evaluation index system in Henan Province, including the four-level indicators, 12 secondary indicators and 28 level indicators.

\section{Henan Province Cultural Industry Competitiveness Evaluation Case Study}

Based on comparative analysis of regional economic and social development based on international experience, a GDP per capita of more than \$3,000, people's living standards go beyond the poverty line after a well-off stage, the social demand for cultural products and services will produce a significant bulge phenomenon, cultural industries grew rapidly, driven by strong demand, and become an important economic growth point and pillar industries of the national economy. Therefore, we selected 2013 per capita GDP more than 10 provinces and municipalities of $\$ 5000$ as a sample, data from the 2013 National Economic and Social Development provinces Statistical Bulletin, Statistical Yearbook and the 2013 China Statistical Yearbook. This paper uses SPSS statistical software factors in the analysis of regional cultural industry competitiveness factors were analyzed and evaluated through a comparative study between regions, determining factors and the importance of the Culture of industrial competitiveness, so as to further measures research and development strategy to provide the basis to build. By raw data are normalized, after obtaining the correlation coefficient between the index matrix, the rotation factor obtained by maximum size of the matrix characteristic root, the contribution rate and the cumulative contribution rate.

By calculating the results can be seen: one in Henan cultural industry competitiveness evaluation index's main characteristic roots have five, the contribution rate is $35.830 \%, 20.091 \%, 12.735 \%$, $12.545 \%$ and $11.329 \%$, the cumulative contribution rate $92.531 \%$. Illustrated by the following data transformation, which features five root out the information reflected in over $90 \%$ of all the amount of information, therefore, can use the first five common factors of change on behalf of the whole sample of changes related variables. And it can be seen from the matrix of factor loadings after rotation, Factor 1 contains the Cultural Industry Competitiveness Evaluation System in Henan Province in six three indicators, and

Henan Province is closely related to the cultural industry competitiveness evaluation factors of cultural production capacity conditions, therefore, the author defined as a common factor in Henan Province Cultural Industry Competitiveness Evaluation of industrial productivity factor; common 
factor 2 contains five three indicators, closely related to cultural industries spending power conditions, it is defined as industry spending power factor; common factor 3 includes six three indicators that are closely related to cultural industries resource capacity conditions, so called industrial culture resources, power factor; common factor 4 contains six three indicators are closely related to government policy implementation capacity of these conditions indicators and development of cultural industries, so called government executive power factor; common factor 5 includes five three indicators, and the development of cultural industries industry innovation ability condition closely

Off, so called industrial innovation factor. In other words, the key to the competitiveness of Henan cultural industry development path to the realization that the cultural industry productivity conditions, consumer spending conditions, resources, power, the government execution conditions and industrial innovation conditions, but also that the balanced development of these five areas.

Second, the 10 provinces and cities nationwide comprehensive Cultural Industry Competitiveness Evaluation Index, Guangdong Province and Shandong Province resident in the first group, the more obvious advantages, the advantages of Guangdong Province from its balanced development of all five factors, the advantages of Shandong Province, the source in which the balanced development of four factors. Henan Province Cultural Industry Competitiveness Evaluation index ranked No. 6, with the grand goal of building a culture of Henan province there is a big gap.

The third is specific to the five factors, Guangdong, Shanghai and Beijing in the cultural industry productivity advantage is obvious, its comprehensive index exceeded 10 times around the other provinces, which also confirmed this from another point of three provinces, City cultural industry accounts for more than 5\% of GDP and become a pillar industry of the national economy facts. In addition, Henan Province in the cultural industry productivity significant gaps and the three provinces, the overall level of respect in the other four factors is not high, but develop a more balanced, there is no obvious shortcomings, but there are few bright spots, such as Inner Mongolia and Liaoning provinces in the cultural industry in terms of innovation, the government of Shandong Province in terms of execution, the cultural industry in Shanghai in terms of spending power has the characteristics and advantages.

\section{The Strategic Path Analysis to Improve Henan Province Cultural Industry Competitiveness}

Make Efforts to Foster New Cultural Market Players and Forge New Cultural Industry Chain. First, actively promote the management of cultural institutions restructuring, efforts to form a group with strong independent innovation capacity and market competitiveness of cultural enterprises and enterprise groups; second is to accelerate the transformation of state-owned cultural enterprises into companies, for cultural enterprises to truly become autonomous, self-restraint, self-development of the market players; third is to foster the cultural industry strategic investors, the use of market mechanisms to capital as a link, focusing on cultivating and developing a number of trans-regional, cross-media, cross-ownership of large-scale cultural enterprises and enterprise groups, Henan Province to become the leading force in the cultural market and cultural industries of strategic investors. On this basis, and constantly open up new areas of Henan cultural industry with high added value, high creativity, high circulation and forms an extension of industrial chain, high creativity (news content, quality books, highlights) is the upstream industry chain, high liquidity (Business Development) is the cultural industry chain downstream, access to high value-added industry chain is the cultural destination.

Develope Cultural and Creative Industries and Create Cultural Industry Group. We should give full play to the incubation function of gathering and industrial park in Henan Province, to the cultural and creative design as a leader, gathering all kinds of factors of production. Focus on the development of manufacturing design creativity, culture media and creative, artistic and cultural creation, cultural traditions and heritage conservation, cultural and creative digital services, cultural and creative architecture, consulting and creative planning leisure consumption creative industries, cultural and creative industries to form a complete chain. At the same time, should be based on the 
characteristics of different cities and regions, scientific planning of cultural industries based high-tech industrial parks and bases, and the construction of the park as a base to promote and facilitate the development of the province's cultural industry breakthrough, and the formation of a number of distinctive characteristics creative industries gathering area, improving cultural industrial scale, intensive level.

The text of the VLSI research integration build cultural industry innovation system government, manufacturing enterprises, cultural enterprises and research institutions is a major player in industrial innovation. Manufacturing technology, production advantages and developed market system, can provide material security, cultural enterprises and research institutions knowledge advantage and knowledge innovation capacity development of cultural industries, can inject new vitality into the development of manufacturing industry. Zhengzhou City, actively promote the linkage grafting manufacturing, cultural industries and School of Design, Jiangnan University, Zhengzhou (National) Industrial Design Park has produced good government, industry and research integration demonstration effect text. Henan Province should implement government guidance and market-driven businesses operate, supply and demand side to take direct docking, project commissioned research and other forms of production, the formation of cultural products and equipment research and development, production, sales integration system. At the same time, with complete technical infrastructure, industrial development preferential policies to encourage internationally renowned cultural enterprises regional headquarters, high value-added manufacturing sector, R \& D centers, procurement centers and service outsourcing base in Henan Province, the promotion of cultural industries and manufacturing bidirectional chain extension to form a mutual occasion, coordinated development of the situation.

\section{Acknowledgements}

Fund Project: 2015 Annual Science and Technology Department of Henan Province Soft Science Planning Project (Item Number: 152400410306)

\section{References}

[1] Wan Bo, Huang Shouhong. Hehai University, Vol. 2 (2009) No 11, p.43-48

[2] Scott Allen. World Cultural Industry Development Report frontier, Vol. 12 (2004) No 27, p.125-126

[3] Xiang Yong. North Frontier Culture Industry Report, Vol. 30 (2004) No 19, p.15-16

[4] MARK J. Capital and Class, Vol. 3(2004) No 28, p.199-210

[5] Wang Yi. Seeking, Vol. 2 (2007) No 27, p.39-41

[6] Li Yichun. Economic and Social Systems, Vol. 2 (2006) No 27, p. 99-104 